\title{
OPEN Impact of respiratory infectious epidemics on STEMI incidence and care
}

S. Macherey ${ }^{1}$, M. M. Meertens ${ }^{1}$, C. Adler ${ }^{1}$, S. Braumann ${ }^{1}$, S. Heyne ${ }^{1}$, T. Tichelbäcker ${ }^{1}$, F. S. Nießen ${ }^{1}$, H. Christ ${ }^{2}$, I. Ahrens ${ }^{3}$, F. M. Baer ${ }^{4}$, F. Eberhardt ${ }^{5}$, M. Horlitz ${ }^{6}$, A. Meissner ${ }^{7}$, J. M. Sinning ${ }^{8}$, S. Baldus ${ }^{1} \&$ S. Lee ${ }^{1 \bowtie}$

The effect of respiratory infectious diseases on STEMI incidence, but also STEMI care is not well understood. The Influenza 2017/2018 epidemic and the COVID-19 pandemic were chosen as observational periods to investigate the effect of respiratory virus diseases on these outcomes in a metropolitan area with an established STEMI network. We analyzed data on incidence and care during the COVID-19 pandemic, Influenza 2017/2018 epidemic and corresponding seasonal control periods. Three comparisons were performed: (1) COVID-19 pandemic group versus pandemic control group, (2) COVID-19 pandemic group versus Influenza 2017/2018 epidemic group and (3) Influenza 2017/2018 epidemic group versus epidemic control group. We used Student's t-test, Fisher's exact test and Chi square test for statistical analysis. 1455 patients were eligible. The daily STEMI incidence was 1.49 during the COVID-19 pandemic, 1.40 for the pandemic season control period, 1.22 during the Influenza 2017/2018 epidemic and 1.28 during the epidemic season control group. Median symptomto-contact time was 180 min during the COVID-19 pandemic. In the pandemic season control group it was $90 \mathrm{~min}(p=0.183)$, and in the Influenza $2017 / 2018$ cohort it was $90 \mathrm{~min}$, too $(p=0.216)$. Interval in the epidemic control group was $79 \min (p=0.733)$. The COVID-19 group had a door-to-balloon time of $49 \mathrm{~min}$, corresponding intervals were $39 \mathrm{~min}$ for the pandemic season group $(p=0.038), 37 \mathrm{~min}$ for the Influenza 2017/2018 group ( $p=0.421)$, and $38 \mathrm{~min}$ for the epidemic season control group $(p=0.429)$. In-hospital mortality was $6.1 \%$ for the COVID-19 group, 5.9\% for the Influenza 2017/2018 group $(p=1.0), 11 \%$ and $11.2 \%$ for the season control groups. The respiratory virus diseases neither resulted in an overall treatment delay, nor did they cause an increase in STEMI mortality or incidence. The registry analysis demonstrated a prolonged door-to-balloon time during the COVID-19 pandemic.

$\begin{array}{ll}\begin{array}{l}\text { Abbreviations } \\ \text { ASA }\end{array} & \text { Aspirin, acetylsalicylic acid } \\ \text { CABG } & \text { Coronary artery bypass graft } \\ \text { CK } & \text { Creatine kinase } \\ \text { CFX } & \text { Circumflex artery, Ramus circumflexus } \\ \text { Clo } & \text { Clopidogrel } \\ \text { ECG } & \text { Electrocardiogram } \\ \text { EMS } & \text { Emergency medical service } \\ \text { KIM } & \text { The Cologne Infarction Model Registry } \\ \text { LAD } & \text { Left artery descending } \\ \text { LBBB } & \text { Left bundle branch block } \\ \text { LIMA } & \text { Left internal mammary artery } \\ \text { PCI } & \text { Percutaneous coronary intervention } \\ \text { Pra } & \text { Prasugrel }\end{array}$

${ }^{1}$ Clinic III for Internal Medicine, University of Cologne, Faculty of Medicine and University Hospital Cologne, Kerpener Str. 62, 50937 Cologne, Germany. ${ }^{2}$ Institute of Medical Statistics and Computational Biology, University of Cologne, Cologne, Germany. ${ }^{3}$ Department of Cardiology, Augustinerinnen Hospital, Cologne, Germany. ${ }^{4}$ Department of Cardiology, St. Antonius Hospital, Cologne, Germany. ${ }^{5}$ Department of Cardiology, Evangelisches Krankenhaus Kalk, Cologne, Germany. ${ }^{6}$ Department of Cardiology, Krankenhaus Porz am Rhein, Cologne, Germany. ${ }^{7}$ Department of Cardiology, Krankenhaus Köln-Merheim, Cologne, Germany. ${ }^{8}$ Department of Cardiology, St. Vinzenz Hospital, Cologne, Germany. ${ }^{\varpi}$ email: samuel.lee@uk-koeln.de 


$\begin{array}{ll}\text { RCA } & \text { Right coronary artery } \\ \text { RD } & \text { Diagonal branch, Ramus diagonalis } \\ \text { RPLS } & \text { Posterolateral artery branch, Ramus posterolateralis } \\ \text { SARS-CoV-2 } & \text { Severe acute respiratory syndrome coronavirus 2 } \\ \text { STEMI } & \text { ST-elevation myocardial infarction } \\ \text { Tic } & \text { Ticagrelor } \\ \text { TIMI flow grade } & \text { Thrombolysis in myocardial infarction flow grade }\end{array}$

Multiple triggers of ST-elevation myocardial infarction (STEMI) were described previously, but the effect of respiratory infectious diseases on STEMI incidence is not well understood. The effect of these infectious diseases on treatment of patients with STEMI is not well investigated. The Influenza 2017/2018 season and the coronavirus disease 2019 (COVID-19) pandemic were chosen as observational periods to investigate the effect of respiratory virus diseases on STEMI incidence and treatment in a metropolitan area with a preexisting STEMI network. COVID-19 caused by severe acute respiratory syndrome coronavirus 2 (SARS-CoV-2) was declared a pandemic by the World Health Organization on March 11, 20201. Previous studies and expert opinions around the world raised concerns about a trend towards decreased ST-elevation myocardial infarction (STEMI) admissions, prehospital treatment delay, as well as an overwhelmed medical system caused by the pandemic ${ }^{2-7}$. STEMI patients suffer from high mortality and morbidity rates, thus requiring prompt diagnosis and treatment ${ }^{8}$. After the initial outbreak in Wuhan, China in December 2019, the first case of COVID-19 was documented in Germany on January 27, 2020. On February 25, 2020, the first person in the German state of North Rhine Westphalia was diagnosed with COVID-19. The government of North Rhine Westphalia issued containment recommendations to hospitals on March 3, 2020, and passed a coronavirus executive order on March 22, 2020 . This lockdown resulted in contact restrictions, remote work and an extreme reduction of public life and mobility.

On the contrary, the Influenza 2017/2018 season-which was declared as epidemic in Europe and was a prototype of a seasonal respiratory infectious disease with high disease burden-did not lead to the implementation of comparable containment recommendations or executive orders ${ }^{10}$. The influenza season in general was described as predictor of increased incidence of myocardial infarction and might raise the cardiovascular risk of patients with coronary artery disease ${ }^{11-13}$. During the Influenza 2017/2018 epidemic in Germany 334,000 patients were diagnosed with influenza, of these, 60,000 required hospitalization ${ }^{10}$. The Influenza 2017/2018 epidemic resulted in a doubling of the registered influenza-caused deaths compared to the prior season $2016 / 2017^{10}$. The effect of this disease burden on the treatment of STEMI patients was not investigated before.

The current study aims to clarify the role of the recurrent influenza season on STEMI care exemplified by the 2017/2018 season. This study was also conducted to evaluate the hypothesized concerns about a decrease in STEMI admissions and treatment delay during the COVID-19 pandemic. Specifically, it addressed patient- and system-related delay in a myocardial infarction network in the city of Cologne, Germany ${ }^{14,15}$.

\section{Methods}

Study design and population. This prospective, observational, multicenter cohort study included all STEMI patients diagnosed and treated within the period of December 1, 2013 to April 30, 2020 in the city of Cologne, Germany. The concept of the Cologne Infarction Model network ("Kölner Infarkt Modell", KIM) has been described previously ${ }^{14,15}$. Briefly, KIM is a co-operation between all sixteen hospitals and the emergency medical services in the $400 \mathrm{~km}^{2}$ area of Cologne, Germany, populated by about 1 million people. Seven out of sixteen hospitals feature percutaneous coronary intervention (PCI) capabilities $24 \mathrm{~h}$ a day, 7 days a week. STEMI patients who first presented to emergency medical service were directly transferred to the catheterization laboratories of those PCI centers. Patients who presented to non-PCI hospitals were immediately transferred to hospitals with catheterization laboratory capabilities. Guideline conform STEMI diagnosis required typical symptoms in the presence of either ST-segment elevation in at least two contiguous leads or assumed new onset left bundle branch block (LBBB) on a 12-lead electrocardiogram ${ }^{8,16}$. All patients with STEMI and a complete report on treatment periods reflecting pre-clinical and in-hospital delay were eligible for the current analysis. The study complies with the Declaration of Helsinki. Ethical approval was issued by the local ethics committee of the University of Cologne (No. 06-064) and written informed consent was obtained from all patients. The KIM registry is funded by the KIM registered association.

Observational period. The first wave of the COVID-19 pandemic began on January 27, 2020 and ended around April 30, 2020 in Germany ${ }^{17}$. We chose this timeframe for the COVID-19 pandemic observational group. This group was compared to a seasonal control group (pandemic season control group), including all patients treated between January 27 and April, 30 between the years 2014 to 2019. All other patients were excluded because of a potential seasonal effect on health care provision and patients' behavior.

The Influenza 2017/2018 epidemic began on December 25, 2017 and ended around April 30, 2018 in Germany $^{10}$. The Influenza 2017/2018 epidemic group itself was compared to a corresponding control group (epidemic season control group) treated between December 25 and April 30 during the prior years. Moreover, a direct comparison of the COVID-19 pandemic and the Influenza 2017/2018 epidemic group was performed.

Treatment periods. To address the hypothesized effect of the COVID-19 pandemic and Influenza 2017/2018 epidemic on STEMI treatment time indicators were defined as follows: (1) symptom-to-contact time (S2C, defined as the period from symptom-onset to first medial contact), (2) contact-to-balloon time (C2B, defined as the period from first medical contact to balloon inflation), and (3) door-to-balloon time (D2B, defined as the period from arrival at the PCI-hospital to balloon inflation). Additionally, data on mortality, procedural 
results and peri-interventional complications were extracted from the registry. Peri-interventional data included the access route, culprit lesion, antiplatelet therapy, the maximum amount of creatin kinase, local bleeding rates and peri-interventional ventricular arrhythmia.

Statistical analysis. Data were described using median [interquartile range], or mean values ( \pm standard deviation), or frequencies and percentages. Extreme values suspected to be implausible data were censored. The Student's t-test, Fisher's exact test and Chi square test were used for statistical analyses. All reported $p$-values were two-sided, and $p$-values less than 0.05 were considered statistically significant. Statistical analyses were performed using SPSS Statistics Version 26.0.0 (NY: IBM Corp., Armonk).

Ethics approval. The study complies with the Declaration of Helsinki. Ethical approval was issued by the local ethics committee of the University of Cologne.

Consent to participate. Written informed consent was obtained from all patients.

\section{Results}

1455 patients were eligible for statistical analysis. The COVID-19 pandemic group included 82 patients and the corresponding pandemic season control group had 358 patients. The Influenza 2017/2018 epidemic group included 54 patients, and the corresponding epidemic season control group consisted of 366 patients. The daily incidence of STEMI was 1.49 during the COVID-19 pandemic and $1.40(p=0.677)$ for the pandemic season control group. Corresponding daily STEMI incidence was 1.22 during the Influenza 2017/2018 epidemic, and 1.28 during the epidemic season control period.

Pre-clinical and baseline data. Baseline characteristics are summarized in Table 1a, b. Mean age was 65.7 years in the COVID-19 pandemic group and 63.5 years in the Influenza 2017/2018 epidemic group. Corresponding mean age was 63.6 for seasonal epidemic and pandemic control group. Patients exhibited similar baseline characteristics regarding gender, heart rate at presentation, and initial systolic blood pressure. Documented ST-segment elevation in at least two contiguous leads during 12-lead ECG was the predominant manifestation of STEMI, whereas assumed new onset LBBB occurred less frequently. During the pre-clinical course, $18.2 \%$ of patients in the COVID-19 pandemic group suffered from cardiac arrest requiring resuscitation. The rate of cardiac arrest was numerically lower during the Influenza 2017/2018 epidemic $(p=0.299)$. None of the patients in the COVID-19 pandemic group had a SARS-CoV-2 infection. The results of influenza testing and the use of antiviral therapy were not documented in the KIM registry.

\begin{tabular}{|c|c|c|c|c|c|c|}
\hline & Total cohort $\mathrm{N}=1455(\%)$ & $\begin{array}{l}\text { COVID-19 pandemic } \\
\text { group } \mathrm{N}=82(\%)\end{array}$ & $\begin{array}{l}\text { Pandemic season control } \\
\text { group } \mathrm{N}=358(\%)\end{array}$ & $p$-value & & \\
\hline \multicolumn{7}{|c|}{ (a) Baseline characteristics COVID-19 pandemic analysis } \\
\hline Age, years, mean & 63.4 & 65.7 & 63.6 & 0.192 & & \\
\hline Gender, male & $1010 / 1412(71.7)$ & $59 / 81(72.8)$ & $231 / 346(66.7)$ & 0.047 & & \\
\hline $\begin{array}{l}\text { Initial heart rate, bpm, } \\
\text { mean }\end{array}$ & 80 & 82 & 78.2 & 0.495 & & \\
\hline $\begin{array}{l}\text { Initial systolic blood pres- } \\
\text { sure, mmHg, mean }\end{array}$ & 139.5 & 132.4 & 138.1 & 0.593 & & \\
\hline Preclinical cardiac arrest & $181 / 1053(17.2)$ & $6 / 33(18.2)$ & $49 / 256(19.1)$ & 1.0 & & \\
\hline \multicolumn{7}{|l|}{ STEMI } \\
\hline New LBBB & $55 / 1269(4.3)$ & $0 / 72(0)$ & $15 / 307(4.9)$ & \multirow{2}{*}{0.085} & & \\
\hline \multirow[t]{2}{*}{ ST-Segment elevation } & $1214 / 1269(95.7)$ & $72 / 72(100)$ & $292 / 307(95.1)$ & & & \\
\hline & Total cohort $\mathrm{N}=1455(\%)$ & $\begin{array}{l}\text { Influenza 2017/2018 } \\
\text { epidemic group } \mathrm{N}=54 \\
(\%)\end{array}$ & $\begin{array}{l}\text { Epidemic season control } \\
\text { group } N=366(\%)\end{array}$ & $p$-value & $\begin{array}{l}\text { COVID-19 pandemic } \\
\text { group } \mathrm{N}=82(\%)\end{array}$ & $\begin{array}{l}\text {-value (Influenza } \\
\text { epidemic vs. COVID-19 } \\
\text { pandemic group) }\end{array}$ \\
\hline \multicolumn{7}{|c|}{ (b) Baseline characteristics Influenza 2017/2018 epidemic analysis } \\
\hline Age, mean & 63.4 & 63.5 & 63.6 & 0.891 & 65.7 & 0.571 \\
\hline Gender, male & $1010 / 1412(71.7)$ & $41 / 54(75.9)$ & $231 / 352(65.6)$ & 0.152 & $59 / 81(72.8)$ & 0.841 \\
\hline $\begin{array}{l}\text { Initial heart rate, bpm, } \\
\text { mean }\end{array}$ & 80 & 83 & 78 & 0.297 & 82 & 0.918 \\
\hline $\begin{array}{l}\text { Initial systolic blood pres- } \\
\text { sure, } \mathrm{mmHg} \text {, mean }\end{array}$ & 139.5 & 146.8 & 138.4 & 0.271 & 132.4 & 0.208 \\
\hline Preclinical cardiac arrest & $181 / 1053(17.2)$ & $3 / 35(8.6)$ & $53 / 272(19.5)$ & 0.161 & $6 / 33(18.2)$ & 0.299 \\
\hline \multicolumn{7}{|l|}{ STEMI } \\
\hline New LBBB & $55 / 1269(4.3)$ & $1 / 51(2)$ & $14 / 382(4.5)$ & \multirow{2}{*}{0.705} & $0 / 72(0)$ & \multirow{2}{*}{0.415} \\
\hline ST-Segment elevation & $1214 / 1269(95.7)$ & $50 / 51(98)$ & $296 / 310(95.5)$ & & $72 / 72(100)$ & \\
\hline
\end{tabular}

Table 1. Baseline characteristics. STEMI ST-segment elevation myocardial infarction, $L B B B$ left bundle branch block. 
Treatment periods. COVID-19 pandemic. The treatment periods are summarized in Table $2 \mathrm{a}$, b, and visualized in Fig. 1. Patients in the COVID-19 pandemic group had a median S2C time of 180 [30-390] minutes which was longer than the pandemic season control group (90 [30-351] minutes, $p=0.183$ ). The median C2B time was 89 [69-108] minutes for the COVID-19 pandemic and 78 [64-95] minutes for the pandemic season control group $(p=0.097)$. Corresponding times for the D2B interval were 49 [27.3-73.3] and 39 [29.8-51.3] minutes $(p=0.038)$. The median length of hospital stay was 5 days for both groups $(p=0.529)$.

Influenza 2017/2018 epidemic. Patients in the Influenza 2017/2018 epidemic group had a median S2C time of 90 [30-240] minutes, which was longer than the epidemic season control group (82.5 [30-300] minutes, $p=0.788$ ). The median C2B time was 80 [63-97.5] minutes for the Influenza 2017/2018 epidemic and 79 [63-95]

\begin{tabular}{|c|c|c|c|c|c|c|}
\hline & Total cohort $N=1455$ & $\begin{array}{l}\text { COVID-19 pandemic } \\
\text { group } \mathrm{N}=82\end{array}$ & $\begin{array}{l}\text { Pandemic season control } \\
\text { group } \mathrm{N}=358\end{array}$ & $p$-value & & \\
\hline \multicolumn{5}{|c|}{ (a) Treatment periods COVID-19 pandemic analysis } & & \\
\hline S2C time & $70[30-246]$ & $180[30-390]$ & $90[30-352]$ & 0.183 & & \\
\hline C2B time & $78[64-94]$ & $89[69-108]$ & $78[64-95]$ & 0.097 & & \\
\hline D2B time & $39[29-55]$ & $49[27.3-73.3]$ & $39[29.8-51.3]$ & $0.038^{*}$ & & \\
\hline \multirow[t]{2}{*}{$\begin{array}{l}\text { Length of hospital stay } \\
\text { (days) }\end{array}$} & $5[4-7.5]$ & $5[4-7]$ & $5[3-7]$ & 0.529 & & \\
\hline & Total cohort $\mathrm{N}=1455$ & $\begin{array}{l}\text { Influenza } 2017 / 2018 \\
\text { epidemic group } \mathrm{N}=54\end{array}$ & $\begin{array}{l}\text { Epidemic season control } \\
\text { group } N=366\end{array}$ & $p$-value & $\begin{array}{l}\text { COVID-19 pandemic } \\
\text { group } N=82\end{array}$ & $\begin{array}{l}p \text {-value (Influenza } \\
\text { epidemic vs. COVID-19 } \\
\text { pandemic group) }\end{array}$ \\
\hline \multicolumn{7}{|c|}{ (b) Treatment periods Influenza 2017/2018 epidemic analysis } \\
\hline S2C time & $70[30-246]$ & $90[30-240]$ & $82.5[30-300]$ & \begin{tabular}{|l|}
0.788 \\
\end{tabular} & $180[30-390]$ & 0.216 \\
\hline C2B time & 78 [64-94] & $80[63-97.5]$ & 79 [63-95] & 0.733 & 89 [69-108] & 0.274 \\
\hline D2B time & 39 [29-55] & 37 [29.5-60] & 38 [27-51] & 0.429 & 49 [27.3-73.3] & 0.421 \\
\hline $\begin{array}{l}\text { Length of hospital stay } \\
\text { (days) }\end{array}$ & $5[4-7.5]$ & $5[3-8.3]$ & $5[4-8]$ & 0.816 & $5[4-7]$ & 0.834 \\
\hline
\end{tabular}

Table 2. Time intervals. $S 2 C$ symptom-to-contact time, $C 2 B$ contact-to-balloon time, $D 2 B$ door-to-balloon time, $N 2 B$ needle-to-balloon time; ${ }^{*}$ : statistical significant difference. Median [interquartile range].

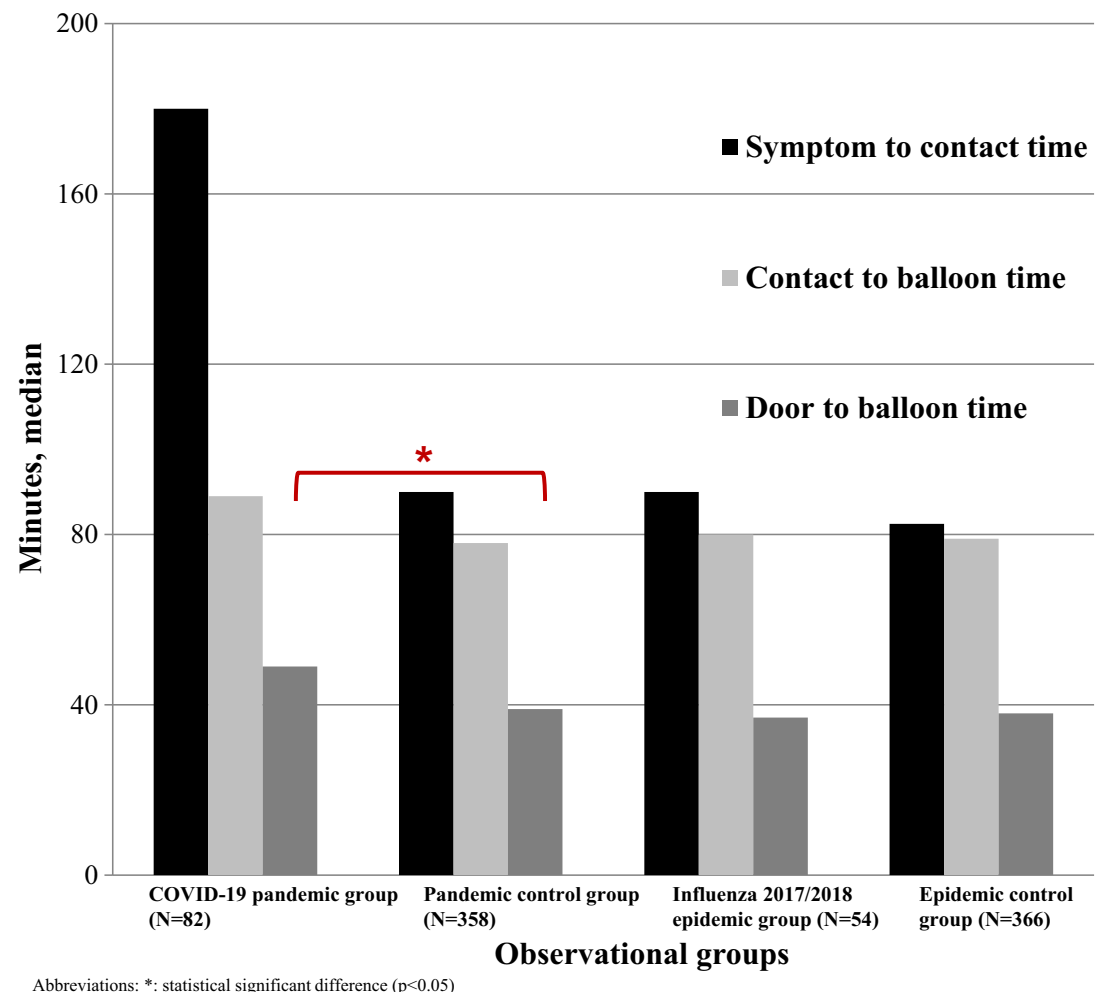

Figure 1. Treatment delay until revascularization. 
minutes for the epidemic season control group $(p=0.733)$. Corresponding D2B intervals were 37 [29.5-60] and 38 [27-51] minutes $(p=0.429)$. The median length of hospital stay was 5 days for both groups $(p=0.816)$.

In the comparison of both respiratory infectious diseases, the COVID-19 pandemic had longer S2C, C2B and D2B intervals, but none of these differences was significantly different (see Table $2 b$ ).

Procedural data. The radial artery was the predominant access route in the COVID-19 pandemic and the Influenza 2017/2018 epidemic group (see Table 3). These proportions were statistically significant different compared to those from the seasonal control groups, as the femoral artery puncture were performed in 64.2 and 70.2 of all procedures in the historical cohorts $(p<0.001)$. Angiography revealed that LAD occlusion was the most frequent cause of STEMI in all patients, but the proportion of LAD occlusion was significantly higher in patients of the Influenza 2017/2018 epidemic group (55.6\%) in comparison to the epidemic season control group (36.7\%, $p=0.011$ ). Myocardial infarction of the inferior wall either caused by occlusion of RCA or subsequent branches was the second most common cause for STEMI. After primary angiography 39 patients were transferred to urgent CABG operation. In the remaining cohort, interventional reperfusion (TIMI I-III) was achieved in all but 142 patients.

Peri-interventional complications occurred in $8.5 \%$ of patients in the COVID-19 pandemic and $5.9 \%$ of patients in the Influenza 2017/2018 epidemic group (see Table 4). The corresponding rates were $14.6 \%$ and $14.8 \%$ for the seasonal control groups. Specifically, in-hospital mortality was $6.1 \%$ for COVID-19 pandemic group and $11.0 \%$ for the pandemic season control group $(p=0.129)$. Corresponding rates were $5.9 \%$ for the Influenza $2017 / 2018$ epidemic and $11.2 \%$ for the related epidemic season control group $(p=0.333)$.

\section{Discussion}

Major findings. The incidence of STEMI in the metropolitan area of Cologne was steady during the first wave of COVID-19 pandemic or the Influenza 2017/2018 epidemic. We observed adequate intervals between first medical contact and revascularization. In detailed analysis, both diseases demonstrated a trend towards an increased patient-related delay compared to each corresponding seasonal control group without significant differences. Additionally, the current analysis showed a prolonged door-to-balloon time during the COVID-19 pandemic. The direct comparison of the COVID-19 pandemic and Influenza 2017/2018 epidemic did not demonstrate a significant difference regarding system- or patient-related delay.

\begin{tabular}{|c|c|c|c|c|c|c|c|c|}
\hline & $\begin{array}{l}\text { Total cohort } \\
\mathrm{N}=1455(\%)\end{array}$ & $\begin{array}{l}\text { COVID-19 } \\
\text { pandemic group } \\
\mathrm{N}=82(\%)\end{array}$ & $\begin{array}{l}\text { Pandemic season } \\
\text { control group } \\
\mathrm{N}=\mathbf{3 5 8}(\%)\end{array}$ & $\begin{array}{l}\text { p-value (COVID- } \\
19 \text { pandemic vs. } \\
\text { pandemic season } \\
\text { control group) }\end{array}$ & $\begin{array}{l}\text { Influenza } \\
2017 / 2018 \\
\text { epidemic group } \\
\mathrm{N}=54(\%)\end{array}$ & $\begin{array}{l}\text { Epidemic season } \\
\text { control group } \\
\mathrm{N}=366(\%)\end{array}$ & $\begin{array}{l}\text { p-value } \\
\text { (Influenza } \\
2017 / 2018 \\
\text { epidemic vs. } \\
\text { epidemic season } \\
\text { control group) }\end{array}$ & $\begin{array}{l}\text { p-value } \\
\text { (Influenza } \\
2017 / 2018 \\
\text { epidemic vs. } \\
\text { COVID-19 } \\
\text { pandemic group) }\end{array}$ \\
\hline \multicolumn{9}{|l|}{ Access route } \\
\hline Radial access & $540 / 1303(41.4)$ & $55 / 82(67.1)$ & $122 / 341(35.8)$ & \multirow{2}{*}{$<0.001^{\star}$} & $30 / 47(63.8)$ & $104 / 349(29.8)$ & \multirow{2}{*}{$<0.001^{\star}$} & \multirow{2}{*}{0.705} \\
\hline Femoral access & $763 / 1303(58.6)$ & $27 / 82(32.9)$ & $219 / 341(64.2)$ & & $17 / 47(36.2)$ & $245 / 349(70.2)$ & & \\
\hline \multicolumn{9}{|l|}{ Culprit lesion $^{a}$} \\
\hline LAD & $585 / 1404(41.7)$ & $41 / 82(50.0)$ & $140 / 357(39.2)$ & 0.082 & $30 / 54(55.6)$ & $134 / 365(36.7)$ & $0.011^{\star}$ & 0.600 \\
\hline $\mathrm{RD}$ & $47 / 1404(3.3)$ & $4 / 82(4.9)$ & $10 / 357(2.8)$ & 0.308 & $1 / 54(1.9)$ & $12 / 365(3.3)$ & 1.0 & 0.648 \\
\hline CFX & $195 / 1404(13.9)$ & $6 / 82(7.3)$ & $57 / 357(16.0)$ & 0.053 & $8 / 54(14.8)$ & $58 / 365(15.9)$ & 1.0 & 0.248 \\
\hline RPLS & $69 / 1404(4.9)$ & $2 / 82(2.4)$ & $22 / 357(6.2)$ & 0.280 & $1 / 54(1.9)$ & $29 / 365(7.9)$ & 0.154 & 1.0 \\
\hline RCA & $459 / 1404(32.7)$ & $32 / 82(39.0)$ & $117 / 357(32.8)$ & 0.302 & $14 / 54(25.9)$ & $122 / 365(33.4)$ & 0.350 & 0.140 \\
\hline $\begin{array}{l}\text { LIMA-LAD } \\
\text { Bypass graft }\end{array}$ & $5 / 1404(0.4)$ & $1 / 82(1.2)$ & $1 / 357(0.3)$ & 0.339 & $0 / 54(0)$ & $2 / 365(0.5)$ & 1.0 & 1.0 \\
\hline $\begin{array}{l}\text { Venous Bypass } \\
\text { graft }\end{array}$ & $16 / 1404(1.1)$ & $2 / 82(2.4)$ & $3 / 357(0.8)$ & 0.235 & $0 / 54(0)$ & $3 / 365(0.8)$ & 1.0 & 0.518 \\
\hline Other & $36 / 1404(2.6)$ & $3 / 82(3.7)$ & $11 / 357(3.1)$ & 0.732 & $0 / 54(0)$ & $10 / 365(2.7)$ & 0.373 & 0.276 \\
\hline \multicolumn{9}{|c|}{ Postprocedural antiplatelet therapy } \\
\hline $\mathrm{ASA}+\mathrm{Clo}$ & $196 / 1261(15.5)$ & $8 / 75(10.7)$ & $53 / 322(16.5)$ & 0.285 & $6 / 48(12.5)$ & $61 / 339(18.0)$ & 0.419 & 0.777 \\
\hline $\mathrm{ASA}+$ Pra & $461 / 1261(36.6)$ & $32 / 75(42.7)$ & $114 / 321(35.4)$ & 0.288 & $11 / 48(22.9)$ & $140 / 338(41.4)$ & $0.017^{\star}$ & $0.033^{*}$ \\
\hline $\mathrm{ASA}+\mathrm{Tic}$ & $433 / 1261(34.3)$ & $29 / 75(38.7)$ & $110 / 322(34.2)$ & 0.502 & $24 / 48(50.0)$ & $91 / 339(26.8)$ & $0.002^{*}$ & 0.264 \\
\hline Other & $171 / 1261(13.6)$ & $6 / 75(8.0)$ & $45 / 322(14.0)$ & - & $7 / 48(14.6)$ & $47 / 339(13.9)$ & - & - \\
\hline \multicolumn{9}{|c|}{ Maximum of CK } \\
\hline Mean, U/L & 2115.42 & 2058.86 & 2147.98 & 0.214 & 2061.86 & 2081.8 & 0.988 & 0.338 \\
\hline
\end{tabular}

Table 3. Periprocedural characteristics. $L A D$ left artery descending, $R D$ diagonal branch, $C F X$ circumflex artery, RPLS posterolateral artery branch, $R C A$ right coronary artery, LIMA left internal mammary artery, ASA acetylsalicylic acid, Clo Clopidogrel, Pra Prasugrel, Tic Ticagrelor, CK creatin kinase, ${ }^{*}$ : statistical significant

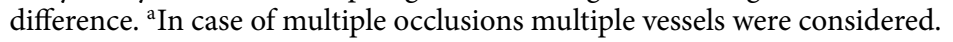




\begin{tabular}{|c|c|c|c|c|c|c|c|c|}
\hline & $\begin{array}{l}\text { Total cohort } \\
N=1455(\%)\end{array}$ & $\begin{array}{l}\text { COVID-19 } \\
\text { pandemic group } \\
\mathrm{N}=82(\%)\end{array}$ & $\begin{array}{l}\text { Pandemic season } \\
\text { control group } \\
\mathrm{N}=358 \text { (\%) }\end{array}$ & $\begin{array}{l}\text { p-value (COVID- } \\
19 \text { pandemic vs. } \\
\text { pandemic season } \\
\text { control group) }\end{array}$ & $\begin{array}{l}\text { Influenza } \\
2017 / 2018 \\
\text { epidemic group } \\
\mathrm{N}=54(\%)\end{array}$ & $\begin{array}{l}\text { Epidemic season } \\
\text { control group } \\
\mathrm{N}=366 \text { (\%) }\end{array}$ & \begin{tabular}{|l|}
-value \\
(Influenza \\
$2017 / 2018$ \\
epidemic vs. \\
epidemic season \\
control group)
\end{tabular} & \begin{tabular}{|l|} 
p-value \\
(Influenza \\
$2017 / 2018$ \\
epidemic vs. \\
COVID-19 \\
pandemic group)
\end{tabular} \\
\hline Death & $146 / 1398(10.4)$ & $5 / 82(6.1)$ & $39 / 355(11.0)$ & 0.225 & $3 / 51(5.9)$ & $41 / 366(11.2)$ & 0.333 & 1.0 \\
\hline Re-Infarction & $12 / 1345(0.9)$ & $2 / 82(2.4)$ & $5 / 341(1.5)$ & 0.625 & $0 / 50(0)$ & $6 / 350(1.7)$ & 1.0 & 0.526 \\
\hline $\begin{array}{l}\text { Ventricular fibril- } \\
\text { lation }\end{array}$ & $22 / 1345(1.6)$ & $0 / 82(0)$ & 6/341 (1.8) & 0.602 & $0 / 50(0)$ & $3 / 349(0.9)$ & 1.0 & - \\
\hline $\begin{array}{l}\text { Access route } \\
\text { bleeding }\end{array}$ & $11 / 1345(0.8)$ & $0 / 82(0)$ & 2/341 (0.6) & 1.0 & $0 / 50(0)$ & 4/349 (1.1) & 1.0 & - \\
\hline
\end{tabular}

Table 4. Periprocedural complication rates. $L A D$ left artery descending, $R D$ diagonal branch, $C F X$ circumflex artery, $R P L S$ posterolateral artery branch, $R C A$ right coronary artery, LIMA left internal mammary artery, ASA acetylsalicylic acid, Clo Clopidogrel, Pra Prasugrel, Tic Ticagrelor, CK creatin kinase, ${ }^{*}$ : statistical significant difference; -: Testing not applicable.

STEMI incidence. The incidence of STEMI was not significantly affected by the respiratory virus diseases in this registry analysis. To our knowledge, this is the first analysis on the effect of the Influenza 2017/2018 season on STEMI care. Over the past years, only few studies investigating the effect of influenza season on myocardial infarction and especially on STEMI incidence or care were published ${ }^{11-13}$. An analysis of the SWEDEHEART registry demonstrated an increased risk of myocardial infarction during the yearly influenza season and a correlation with influenza burden ${ }^{11}$. In a subgroup analysis STEMI patients were not at higher risk for cardiovascular mortality during the influenza season ${ }^{11}$. This result is in line with the current study ${ }^{11}$. Registry data in the United States demonstrated that influenza infection was an independent predictor of in-hospital mortality in patients with myocardial infarction ${ }^{13}$. Concomitant influenza infection and myocardial infarction reduced the rate of revascularization rate significantly ${ }^{12,13}$.

On the contrary, a large amount of studies regarding the COVID-19 pandemic and the effect on patients with STEMI have been published over the last year. Studies done in Europe and China documented a decrease in hospital admissions for STEMI ${ }^{2,18-20}$. De Rosa et al. reported a $26.5 \%$ reduction of STEMI admission during a 1 week period and Scholz et al. detected a $12.6 \%$ decrease during a 1 month period ${ }^{18,20}$. All of these studies were observational studies or registries and might have underreported the true incidence of STEMI during the respiratory virus epidemic and pandemic.

Treatment delay. Regarding the STEMI treatment during the COVID-19 pandemic the S2C, C2B and D2B were longer compared to the pandemic season control group, but only the $\mathrm{D} 2 \mathrm{~B}$ was significantly prolonged. The median S2C was $180 \mathrm{~min}$ and this was a doubling in comparison to the pandemic season control group. As this was not a statistical significant difference, careful interpretation is required. Nevertheless this difference might have clinical impact and is in line with observations in Europe and Asia. De Rosa et al. and Gramegna et al. observed a relevant patient-related delay with a prolonged symptom-to-hospital and contact-to-balloon time during the COVID-19 pandemic ${ }^{18,21}$. Interestingly, these studies took place in outbreak areas during the climax of the early COVID-19 pandemic in Italy. A German analysis of 15,800 patients documented comparable S2C, C2B and D2B times for the COVID-19 pandemic and control group without any significant differences ${ }^{20}$. Multiple studies documented an increase or a trend towards a patient-related delay during the COVID-19 pandemic, but the extent differs between the trials ${ }^{3-5,19,20}$. One potential reason for divergent results is the variance in time frames of COVID-19 pandemic groups. Scholz et al. and Xiang et al. investigated a 1-month period, whereas De Rosa chose a 1-week observation period ${ }^{18-20}$. Daoulah et al. extended the investigation period by analyzing all patients treated over a 4 month period between January 1, 2020 and April 30, 2020 5 . As a result of these heterogeneous approaches, the aforementioned studies came to inconsistent conclusions about the effect of the COVID-19 pandemic on STEMI patient care.

The reasons for patient-related delay are still under consideration. Altruistic behavior has been intensively discussed. One might further argue that patients avoided hospitals as they represent the focus of this viral disease, and because hospitals were confronted by an excessive demand of intensive care unit capacities by COVID-19 patients. These circumstances might also be an explanation for the observed prolonged D2B time in the current analysis. Results by a meta-analysis from Rattka et al. evolving around 50,000 participants also demonstrated a similar increase in D2B time for the COVID-19 group ${ }^{22}$.

Mortality. The registry data indicate a deceased mortality during the Influenza 2017/2018 epidemic and COVID-19 pandemic period. In the setting of the COVID-19 pandemic, we speculate that the availability of resources due to the reduction in elective procedures could have had an impact on these outcomes. On the other hand, a potentially increased local sudden cardiac death rate might have improved the in-hospital outcome (survivorship bias). The current local death rate of the city of Cologne, Germany is not available, hence the true explanation of this phenomenon is still pending and might be addressed in future studies. 
Limitations. Cologne was not highly affected during the observational period of the COVID-19 pandemic ${ }^{17}$. Until April 30, 2020, less than $0.24 \%(\mathrm{~N}=2346)$ of the total population had a SARS-CoV-2 infection ${ }^{17}$. In contrast, reports by De Rosa et al. and Gramegna et al. included hospitals from outbreak areas with much higher incidence of COVID-19 infections. This might not only have influenced the system, but also the patient-related delay $^{18,21}$. Inherent limitations of registry studies also affected the current analysis. A short follow-up period, underreporting of outcome data, limited availability of patient characteristics including comorbidities and treatment data leading to missing data restrict the generalizability of our results. Assessment of subjective variables (e.g. symptom onset) and data management by diverse centers might also influence the study results. One additional limitation is the lack of information on the incidence of influenza infection or antiviral treatment in the cohorts. Unfortunately these variables are not part of the KIM registry, but might have biased the current analysis.

Another important aspect is the local structure of Cologne with a dense structure of hospitals with short transfer periods and the small sample size in the KIM registry. The current analysis is also restricted by the low number of events especially in the observational groups.

\section{Conclusion}

A well-structured co-operation of emergency medical service and local hospitals in a metropolitan area was able to overcome the challenges in the treatment of patients with STEMI during the COVID-19 pandemic and the Influenza 2017/2018 epidemic. In the setting of this network, these respiratory infectious diseases did not result in a significant overall treatment delay. These virus infections did neither cause an increase in "STEMI incidence" section, nor did they raise the STEMI mortality. Nonetheless, both diseases showed a trend towards an increased patient-related delay. Educational programs should address the observed patient-related delay and emphasize the need for immediate contact of the medical system. Additionally, the results demonstrated a significantly prolonged door-to-balloon time during the COVID-19 pandemic. Adequate strategies to minimize this delay and improve health care service balancing prompt treatment and infection protection are needed.

Received: 8 August 2021; Accepted: 15 November 2021

Published online: 29 November 2021

\section{References}

1. Cucinotta, D. \& Vanelli, M. WHO declares COVID-19 a pandemic. Acta Biomed. 91, 157-160 (2020).

2. Wu, J. et al. Patient response, treatments and mortality for acute myocardial infarction during the COVID-19 pandemic. Eur. Heart J. Qual. Care Clin. Outcomes 7, 238-246 (2020).

3. Moroni, F. et al. Collateral damage: Medical care avoidance behavior among patients with myocardial infarction during the COVID-19 pandemic. JACC Case Rep. 2, 1620-1624 (2020).

4. Soylu, K., Coksevim, M., Yanik, A., BugraCerik, I. \& Aksan, G. Effect of Covid-19 pandemic process on STEMI patients timeline. Int. J. Clin. Pract. 75, e14005 (2021).

5. Daoulah, A. et al. STEMI and COVID-19 pandemic in Saudi Arabia. Curr. Probl. Cardiol. 46, 100656 (2020).

6. Tam, C. F. et al. Impact of coronavirus disease 2019 (COVID-19) outbreak on ST-segment-elevation myocardial infarction care in Hong Kong, China. Circ. Cardiovasc. Qual. Outcomes 13, e006631 (2020).

7. Masroor, S. Collateral damage of COVID-19 pandemic: Delayed medical care. J. Card. Surg. 35, 1345-1347 (2020).

8. Ibanez, B. et al. 2017 ESC Guidelines for the management of acute myocardial infarction in patients presenting with ST-segment elevation. Rev. Esp. Cardiol. (Engl. Ed.) 70, 1082 (2017).

9. Coronaschutzverordnung. (2020). February, 092021 https://www.land.nrw/sites/default/files/asset/document/2020-03-30_coron aschvo_idf_der_aendvo.pdf.

10. Robert Koch Institute (RKI). Bericht zur Epidemiologie der Influenza in Deutschland, Saison 2017/2018 (2018).

11. Mohammad, M. A. et al. Association of acute myocardial infarction with influenza: A nationwide observational study. PLoS ONE 15, e0236866 (2020).

12. Vejpongsa, P. et al. Outcomes of acute myocardial infarction in patients with influenza and other viral respiratory infections. Am. J. Med. 132, 1173-1181 (2019).

13. Cardoso, R. et al. In-hospital management and outcomes of patients with acute myocardial infarction and influenza. Am. J. Cardiol. 125, 840-844 (2020).

14. Flesch, M. et al. Implementation of guidelines for the treatment of acute ST-elevation myocardial infarction: The Cologne Infarction Model Registry. Circ. Cardiovasc. Interv. 1, 95-102 (2008).

15. Pfister, R. et al. Impact of the type of first medical contact within a guideline-conform ST-elevation myocardial infarction network: A prospective observational registry study. PLoS ONE 11, e0156769 (2016).

16. Task Force on the Management of STseamiotESoC et al. ESC Guidelines for the management of acute myocardial infarction in patients presenting with ST-segment elevation. Eur. Heart J. 33, 2569-2619 (2012).

17. Robert Koch Institute (RKI). dl-de/by-2-0. February, 092021 https:/www.esri.de/de-de/landingpages/corona-impact-2020/faq.

18. De Rosa, S. et al. Reduction of hospitalizations for myocardial infarction in Italy in the COVID-19 era. Eur. Heart J. 41, 2083-2088 (2020).

19. Xiang, D. et al. Management and outcomes of patients with STEMI during the COVID-19 pandemic in China. J. Am. Coll. Cardiol. 76, 1318-1324 (2020).

20. Scholz, K. H. et al. Impact of COVID-19 outbreak on regional STEMI care in Germany. Clin. Res. Cardiol. 109, 1511-1521 (2020).

21. Gramegna, M. et al. ST-segment-elevation myocardial infarction during COVID-19 pandemic: Insights from a regional public service healthcare hub. Circ. Cardiovasc. Interv. 13, e009413 (2020).

22. Rattka, M. et al. Effect of the COVID-19 pandemic on mortality of patients with STEMI: A systematic review and meta-analysis. Heart 107, 482-487 (2020).

\section{Acknowledgements}

We thank all the physicians who contributed data to the KIM registry. We appreciate the editorial support by Curie L. Lee. 


\section{Author contributions}

S.M., M.M.M. and S.L. wrote the main text and prepared tables and the figure. S.M., H.C., M.M.M. and S.L. did all statistical analyses. C.A., S.B., S.H., T.T. and F.S.N. contributed to the development of the manuscript and collected patients\&apos; data. I.A., F.M.B., F.E., M.H., A.M., J.M.S., S.B. were treating physicians, collected the patients\&apos; data and contributed substantial content to the discussion. All authors reviewed the manuscript.

\section{Funding}

The KIM registry was funded by the KIM registered association. Open Access funding enabled and organized by Projekt DEAL.

\section{Competing interests}

The authors declare no competing interests.

\section{Additional information}

Correspondence and requests for materials should be addressed to S.L.

Reprints and permissions information is available at www.nature.com/reprints.

Publisher's note Springer Nature remains neutral with regard to jurisdictional claims in published maps and institutional affiliations.

(c) (i) Open Access This article is licensed under a Creative Commons Attribution 4.0 International License, which permits use, sharing, adaptation, distribution and reproduction in any medium or format, as long as you give appropriate credit to the original author(s) and the source, provide a link to the Creative Commons licence, and indicate if changes were made. The images or other third party material in this article are included in the article's Creative Commons licence, unless indicated otherwise in a credit line to the material. If material is not included in the article's Creative Commons licence and your intended use is not permitted by statutory regulation or exceeds the permitted use, you will need to obtain permission directly from the copyright holder. To view a copy of this licence, visit http://creativecommons.org/licenses/by/4.0/.

(C) The Author(s) 2021 